\title{
The Impact of Different Types of Permeable Pavement Utilization on Air Temperature and Building Energy Consumption
}

\author{
Andika Citraningrum \\ Department of Civil Engineering, National Central University, Taiwan \\ Email: andikacitra@yahoo.com
}

\begin{abstract}
Pavements are found to be a significant contributor to the urban heat island. One of the strategies to mitigate it is by using permeable pavement. The purpose of this study is to investigate the impact of utilization of permeable pavement on air temperature above the pavement and building energy consumption. Simulation on five types of pavement (dense grade asphalt concrete/DGAC, permeable asphalt concrete/PAC, concrete, permeable interlocking concrete block/PICB, and grass block) using DesignBuilder software with concrete as the base for comparison shows that PICB has the highest air temperature reduction and energy consumption reduction compared to other type of pavements.
\end{abstract}

Keywords: Permeable pavement, air temperature, energy consumption, DesignBuilder

\section{Introduction}

Cities can be several degrees warmer than surrounding regions due to the built environment and the concentration of human activity, a phenomenon referred to as an urban heat island (UHI). This phenomenon happens all over the world. In Taiwan for example, since 1980, temperature increases in the three metropolitan areas of Taipei, Taichung and Tainan have been around two times higher than those in three medium and smaller cities (Hualien, Taitung and Hengchun). Other research result stated that the difference between rural-urban temperature is about $1.83^{\circ} \mathrm{C}$ from $1995-2004$ based on temperature records in 8 major cities in Taiwan. In Taipei City itself, based on temperature change records from 1961-2005, the number of nights above $25^{\circ} \mathrm{C}$ has increased from an average of 35 days/year to more than 100 days/year and the number of daytime temperatures above $37^{\circ} \mathrm{C}$ went from less than 5 days/year to more than 12 days/year, indicating that Taipei City is a clear example for heat island effect.

Pavements are found to be a significant contributor to the UHI temperature increase because (1) they constitute a substantial portion of total urban land coverage and (2) pavements can store and radiate a significant amount of heat. In looking at four cities (Sacramento, Chicago, Salt Lake City and Houston), Rose et al. (2003) found pavements (roads, parking lots, sidewalks, etc.) make up 29-45 percent of the total land coverage, and about half the total UHI contributing surface coverage.

Three commonly suggested strategies to mitigate the heat island effect are by using vegetation, cool roofing, and cool pavements. Cool pavement is pavements that help lower surface temperatures and reduce the amount of heat absorbed into the pavement. Permeable pavement as one type of cool pavements helps to alleviate heat island effect by reducing ambient temperature. 
It has been well documented that heat island increases the demand for air conditioning. Thus, the utilization of permeable pavement that can reduce the ambient temperature also helps to reduce the energy needed to cool the building. Analysis of hourly demand indicates that cooler pavements could save an estimated $100 \mathrm{MW}$ of peak power in LA (Akbari, 2001).

There are many kinds of permeable pavement used on the field, but not many studies have been done to investigate its impact on environment. The paper aims to present and discuss the impact of those different types of permeable pavement on air temperature above each pavement and its impact on building energy consumption when it applied around a building.

\section{Materials and Method}

\subsection{Literature Review}

\subsubsection{Heat Island}

Heat island can be defined as a 'reverse oasis' where air and surface temperatures are hotter than in their surroundings, usually happens in urban area. There are five main causes of heat island formation: reduced evaporation, increased heat storage, increased net radiation, reduced convection, and increased anthropogenic heat (Gartland, 2008). Surface temperatures have an indirect but significant influence on air temperatures, especially in the canopy layer (measured at about the height of people or the lower stories of buildings, between 1.5 and $3 \mathrm{~m}$ above ground), which is closest to the surface. But because air mixes within the atmosphere, the relationship between surface and air temperatures is not constant, and air temperatures typically vary less than surface temperatures across an area. Surface temperatures vary more than air temperatures during the day, but they are fairly similar at night (US EPA, 2008).

\subsubsection{Permeable Pavement}

The general principle of permeable pavement is simply to collect, treat and infiltrate freely any surface runoff to support groundwater recharge. In comparison to traditional drainage systems, storm water retention and infiltration is a sustainable and cost effective process, which is suitable for urban areas (Andersen, 1999). The permeability of the pavement makes it possible for water to infiltrate thoroughly to the soil. This infiltration may increase soil moisture and makes it become softer, thus, it only suitable for light duty and infrequent usage area such as parking area or pedestrian access (Lin, 2003). Figure 1 illustrates the comparison between permeable and traditional pavements. In general, there are three types of permeable pavement that commonly used on the field: permeable asphalt concrete pavement, pervious concrete pavement, and permeable interlocking concrete pavers. 

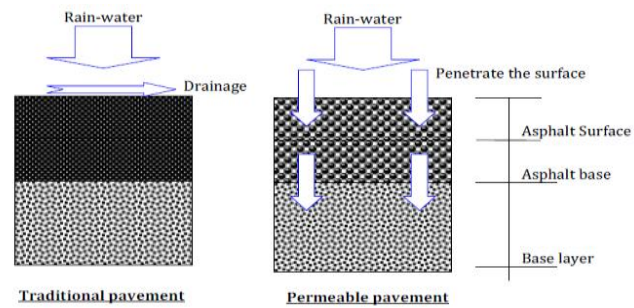

Figure 1: Comparison between permeable and traditional pavements Source: (Lin, 2003)

\subsubsection{Relationship between Permeable Pavement and Air Temperature}

When wet, permeable pavement can lower air temperature through evaporative cooling. Moisture within the pavement structure evaporates as the surface heats, thus drawing heat out of pavement (US EPA, 2008). Due to evaporation, a part of the net downward radiation is converted into latent heat, similar to the phenomena happening at natural surfaces covered by bare soil or vegetation. This means the temperature of the permeable paved surfaces does not escalate as much, and subsequently the underground heat storage and sensible heat exchange between the ground surface and atmosphere are diminished. When dry, the larger voids in permeable pavement increase the available surface area. This condition may limit heat transfer to the lower pavement structure and soils, keeping heat at the pavement's surface (and increasing daytime surface temperatures), but reducing bulk heat storage (reducing release of heat at nighttime).

Previous research on permeable pavement has been done by Kubo et al. to understand the effect of lowering road \& sidewalk surface temperature on air temperature by changing the material from dense graded to cool pavement (water retention pavement and heat-shield pavement). The Computational Fluid Dynamics (CFD) simulation on Ginza (Tokyo) district model for the research shows that when the surface temperatures of the roads and sidewalks were reduced by $10^{\circ} \mathrm{C}$, the air temperatures at $0.5 \mathrm{~m}$ and $1.5 \mathrm{~m}$ above the surface were reduced by $2.13^{\circ} \mathrm{C}$ and $0.73^{\circ} \mathrm{C}$, respectively.

\subsubsection{Building Energy Consumption}

Buildings are known to be one of the largest consumers of electricity; the US Department of Energy estimates that buildings consume $70 \%$ of the electricity in the US (US DOE, 2009). Chan (2004) in his study on energy use found three non-design factors that have significant impact on energy consumption in building: occupancy and management, environmental standard, and climate. Climate affects the energy consumption in a building primarily by influencing the space cooling and heating requirements. The main climatic variables influencing the amount of energy needed for air conditioning are: solar radiation, outside air temperature, wind, rain, and night sky radiation. In Taiwan, according to Taiwan Power Company's report, air conditioning electricity consumption increases about $6 \%$ when the outdoor air temperature increases $1^{\circ} \mathrm{C}$ (Bay and Ong, 2006).

\subsection{Methodology}

In this study, three types of permeable pavements (permeable asphalt pavement, grass block, and permeable interlocking concrete brick) were measured and compared with 
the traditional pavement (concrete and dense-grade asphalt pavement). Site measurement was conducted to collect meteorological and pavement surface temperature data.

The permeable pavement experimental area in the Ministry of Economic Affairs Water Resources Agency, Sindian, New Taipei City, Taiwan was used to collect data for permeable pavement and dense grade asphalt surface temperature, also meteorological data (air temperature, relative humidity, wind velocity, and irradiance) of the area. Easy weather station, thermocouple, and data logger were installed on the site (Figure 2). The data was taken for twelve days from July 1-12, 2011, includes the total of 1728 data observations with ten minutes intervals.

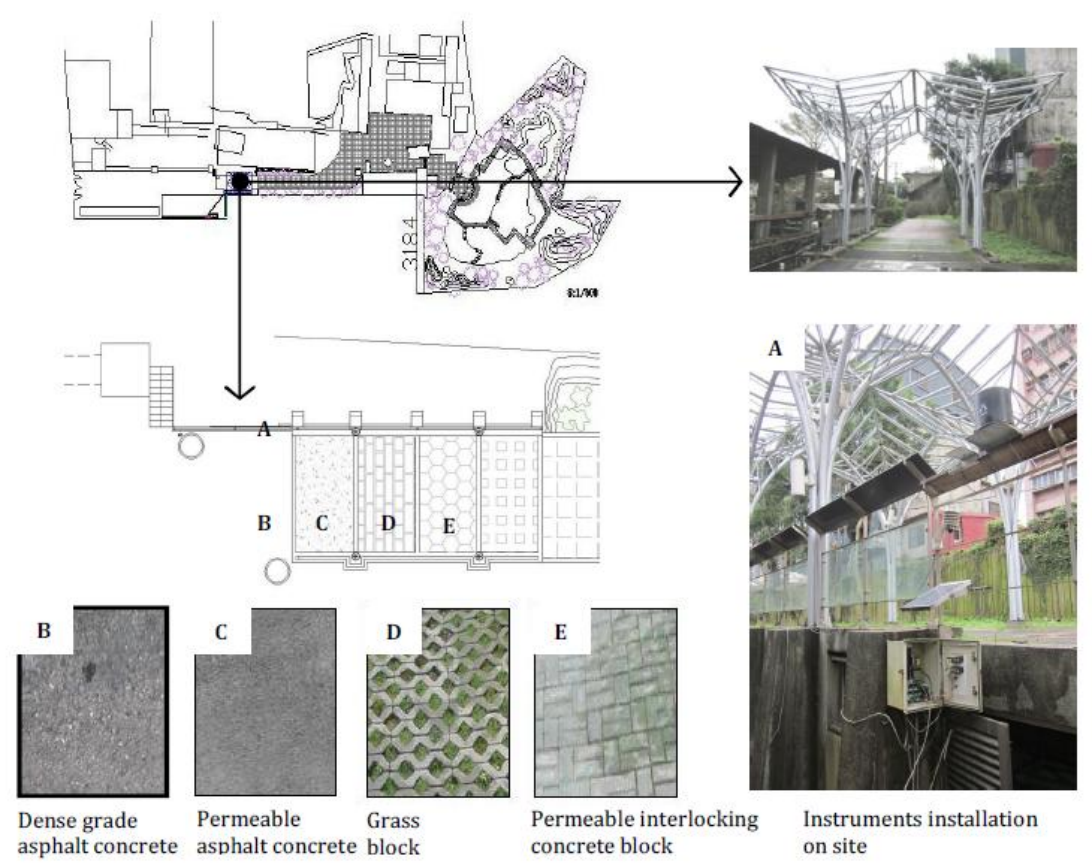

Figure 2: Photo and site plan of the permeable pavement experimental area in Sindian

Other measurement was conducted on Civil Engineering Building, National Central University (NCU), Jhongli, Taiwan to obtain actual data of pavement, wall, and roof surface temperature, also meteorological data of NCU. T-type thermocouple, easy weather station, and data logger were installed on the site (Figure 3). Total eight thermocouples were attached to building surface (one on pavement, six on the wall, and one on the roof). Thermocouples on the wall were attached at the height of $1.5 \mathrm{~m}$ and then every $2 \mathrm{~m}$. Measurement was done from July $16-22,2011$, includes the total of 847 observation with data recording every ten minutes. 

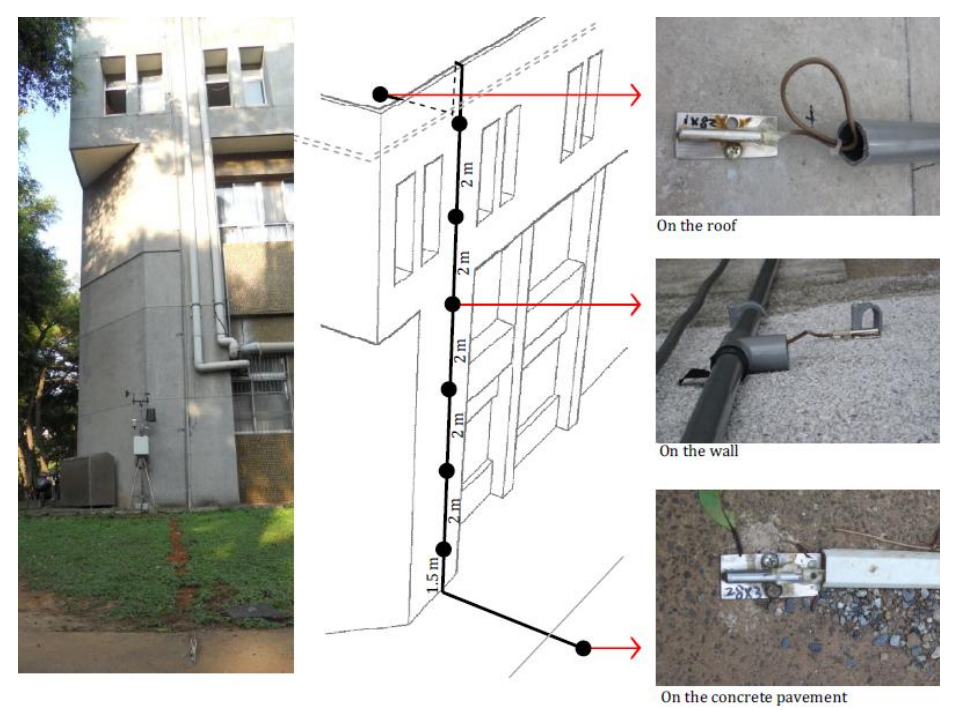

Figure 3: Installation of measurement instruments on Civil Engineering building

Correlation analaysis was used to find the correlation between variables and multiple regression was used to develop the pavement surface temperature model. The surface temperature model along with meteorological data from NCU will be used to approximate the surface temperature of permeable pavement when it is being utilized around NCU library building. The impact of permeable pavement surface temperature on air temperature was investigated using Computational Fluid Dynamics (CFD) simulation in DesignBuilder software. While the impact of permeable pavement utilizations on building energy consumption was simulated using EnergyPlus in DesignBuilder. Figure 4 illustrate the model used in both simulations. The energy consumption in this paper was focused on the air conditioning energy consumption. National Central University (NCU) General Library building was used as the case study for the simulation.
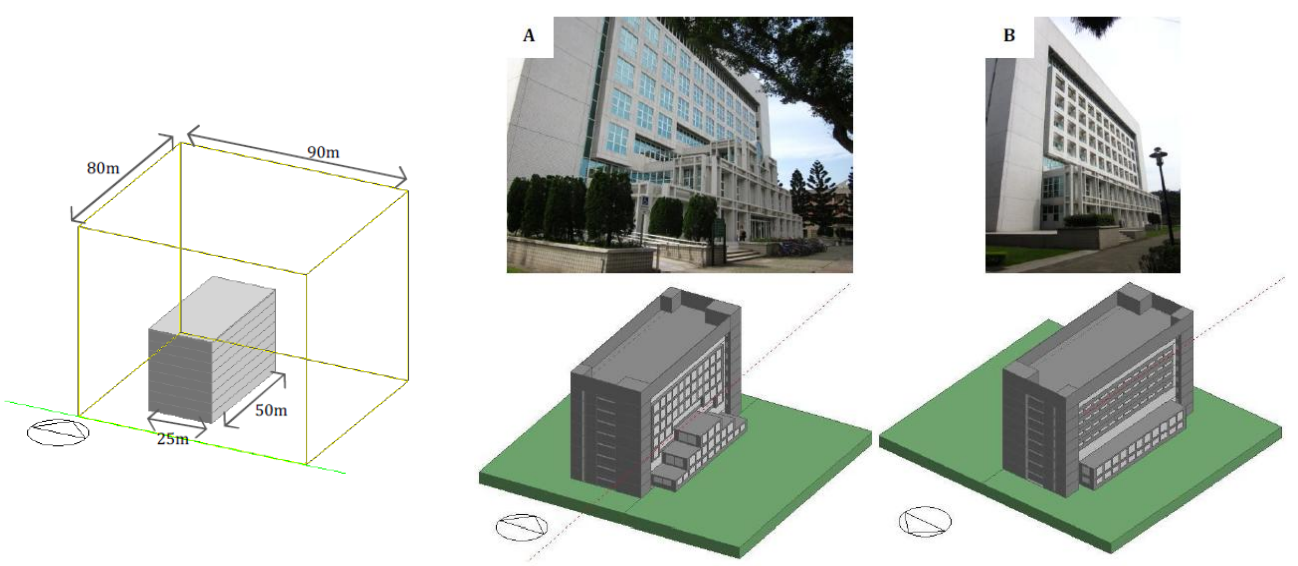

Figure 4: Model for CFD simulation (left); model for EnergyPlus simulation (middle, right) 


\section{Results and Discussions}

\subsection{Site Measurement in Permeable Pavement Experimental Area, Sindian}

Site measurement result shows that pavement temperature changed simultaneously with the change of air temperature and irradiance. Pavement surface temperature increased rapidly after sunrise, reached its peak in midday, and decreased towards sunset time. There are distinctive pavement surface temperature pattern between four types of pavement. At daytime, dense grade asphalt pavement (DGAC) surface temperature is the highest, followed by permeable asphalt concrete (PAC). Grass block and permeable interlocking concrete block (PICB) being the lowest in temperature. At night, all four types of pavement share almost the same temperature (Figure 5).

DGAC surface temperature is higher than PAC from morning until midday with temperature difference reached $14^{\circ} \mathrm{C}$, the highest temperature difference is achieved at around 11.00 AM. But in the afternoon until midnight (around 14.00 PM - $01.00 \mathrm{AM}$ ), surface temperature of DGAC becomes lower than PAC, DGAC's lowest temperature achieved at around $15.00 \mathrm{PM}$. The expected reason for this phenomenon is the high thermal conductivity of DGAC. With higher thermal conductivity, DGAC transfers heat faster than PAC, thus, it heats up quickly as the sun rises. PAC with lower thermal conductivity has slower capability to transfer heat, proved by the time lag from the highest irradiance and PAC highest temperature's time occurrence. In the afternoon, DGAC starts to release its heat as the air temperature and irradiance reduced, but PAC still keeping heats from the previous heating time which makes its surface temperature higher than DGAC.

In the morning until midday, grass block surface temperature is higher than PICB with temperature difference reached $8^{\circ} \mathrm{C}$, the highest temperature difference is achieved at around 10.00 AM. In the afternoon until early in the morning (around 13.00 PM-09.00 AM), surface temperature of grass block becomes lower than PICB, grass block's lowest temperature achieved at around 14.00 PM.

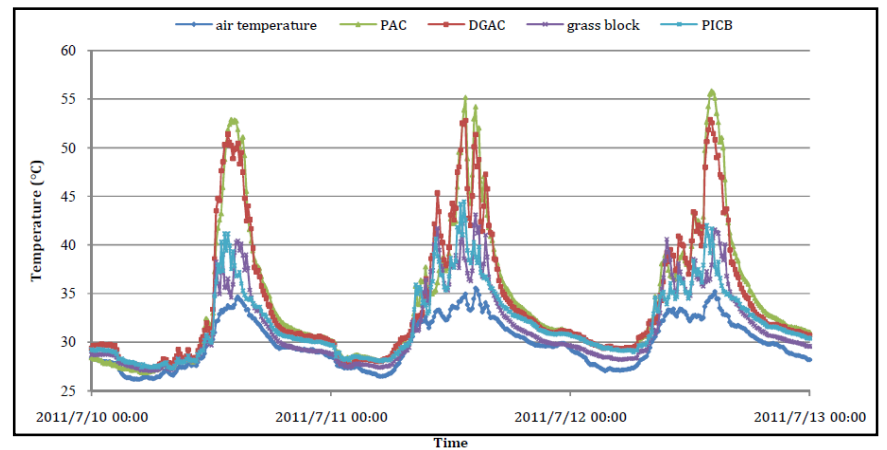

Figure 5: Air temperature and pavement surface temperature profile on July 10-12, 2011

From the correlation analysis result, high positive correlation was found between surface and air temperature (ranged from 0.91-0.93), between surface temperature and irradiance (ranged from 0.72-0.79), also between surface temperature and wind velocity (ranged from 0.70-0.71). High negative correlation was found between relative humidity and surface temperature (ranged from 0.86-0. 89). Thus, the four variables; air temperature, wind velocity, irradiance, and relative humidity will be used in developing linear multiple regression model. 
Pavement, wall, and roof surface temperature changed simultaneously with the change of air temperature and irradiance. Pavement surface is high during midday and decreased towards sunset time. The measurement result from July 16-22, 2011 shows that, compared to the wall and pavement surface temperature, the roof temperature is the highest at daytime, but reduced towards sunset and becomes the lowest during the night. Wall temperatures, as seen in Figure 6, did not show significant temperature difference between each measurement point, the highest temperature difference between measurement point $1.5 \mathrm{~m}$ and $11.5 \mathrm{~m}$ above the pavement is $6.2^{\circ} \mathrm{C}\left(0.5^{\circ} \mathrm{C}\right.$ higher in average $)$. At midnight, pavement, wall, and roof shared almost the same temperature.

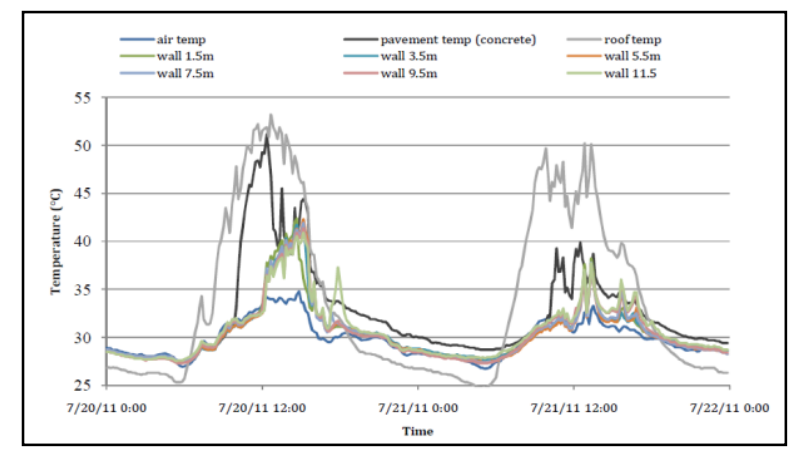

Figure 6: Air temperature, wall, roof, and pavement surface temperature profile on July 2021,2011

\subsection{Surface Temperature Model}

Surface temperature prediction for four types of pavement was established using meteorological data from National Central University measurement on July 20, 2011. Daytime surface temperature prediction was done using meteorological data at $12.40 \mathrm{PM}$, referring to Lin et al. (2007) study which emphasized that the difference in average air temperatures among several pavements is significant only at noon time in summer (particularly during the period 12.00-14.00 PM).

At daytime, as shown in Table 1, surface temperature for dense grade asphalt concrete (DGAC) pavement is $52.2^{\circ} \mathrm{C}$, permeable asphalt concrete (PAC) is $49.9^{\circ} \mathrm{C}$, grass block is $43.3^{\circ} \mathrm{C}$, and permeable interlocking concrete block (PICB) is $42^{\circ} \mathrm{C}$. DGAC has the highest temperature, followed by PAC and grass block, PICB has the lowest temperature. This result fits the surface temperature pattern from the Permeable Pavement Experiment Area as mentioned in section 4.1. This surface temperature will be used to predict the air temperature and compare it with the real condition. Concrete pavement real observation data is used as the base for the comparison. On June 24, 201, $12.40 \mathrm{PM}$, concrete pavement surface temperature is $46.9^{\circ} \mathrm{C}$. 
Table 1: Pavement surface temperature prediction on July 20, 2011 at 12.40 PM

\begin{tabular}{|c|c|c|c|c|c|c|}
\hline $\begin{array}{c}\text { Type of } \\
\text { pavement }\end{array}$ & $\begin{array}{c}\text { Air } \\
\text { temp. } \\
\left({ }^{\circ} \mathrm{C}\right)\end{array}$ & $\begin{array}{c}\text { Irra- } \\
\text { diance } \\
\left(\mathrm{W} / \mathrm{m}^{2}\right) \\
\end{array}$ & $\begin{array}{l}\text { Wind } \\
\text { velocity } \\
(\mathrm{m} / \mathrm{s})\end{array}$ & $\begin{array}{c}\text { Relative } \\
\text { humidity } \\
(\%)\end{array}$ & Surface temp. model & $\begin{array}{c}\text { Surface } \\
\text { temp. } \\
\left({ }^{\circ} \mathrm{C}\right)\end{array}$ \\
\hline DGAC & 34.0 & $\begin{array}{c}1039.3 \\
6\end{array}$ & 1.35 & 66.98 & $\begin{array}{c}\mathrm{y}=-48.080+2.212 \mathrm{x} 1+2.507 \mathrm{x} 2+0.007 \times 3 \\
+0.067 \mathrm{x} 4\end{array}$ & 52.2 \\
\hline PAC & 34.0 & $\begin{array}{c}1039.3 \\
6\end{array}$ & 1.35 & 66.98 & $\begin{array}{c}y=-43.732+3.338 \times 1+2.330 \times 2+0.005 \times 3 \\
+0.074 \times 4\end{array}$ & 49.9 \\
\hline $\begin{array}{l}\text { Grass } \\
\text { block }\end{array}$ & 34.0 & $\begin{array}{c}1039.3 \\
6\end{array}$ & 1.35 & 66.98 & $\begin{array}{c}\mathrm{y}=-0.519+0.723 \mathrm{x} 1+1.154 \mathrm{x} 2+0.006 \mathrm{x} 3- \\
0.040 \mathrm{x} 4\end{array}$ & 43.3 \\
\hline PICB & 34.0 & $\begin{array}{c}1039.3 \\
6\end{array}$ & 1.35 & 66.98 & $y=-4.903+1.022 \times 1+1.307 \times 2+0.003 \times 3-$ & 42.0 \\
\hline
\end{tabular}

Note: $\mathrm{y}=$ pavement surface temp., $\mathrm{x} 1$ = wind velocity, $\mathrm{x} 2$ = air temp., $\mathrm{x} 3=$ irradiance, $\mathrm{x} 4$ = relative humidity

\subsection{The Impact of Permeable Pavement Utilization on Air Temperature above the Pavement}

The effect of permeable pavement utilization on air temperature is simulated using Computational Fluid Dynamics (CFD) package in DesignBuilder software. Meteorological data on July 20, 2011 at $12.40 \mathrm{PM}$ is used as input to represent summer condition, along with the result of pavement surface temperature prediction. The simulation was done on five type of pavements: concrete, dense grade asphalt concrete (DGAC), permeable asphalt concrete (PAC), grass block, and permeable interlocking concrete block (PICB). Concrete is used as the base case simulation, represents the pavement material around NCU main library building. Air temperature above four types of pavement then will be compared to the result of air temperature above concrete pavement. Basic input to the simulation:

- Ambient air temperature $=34^{\circ} \mathrm{C}$

- Irradiance $\quad=1039.36$ $\mathrm{W} / \mathrm{m} 2$

- Wind velocity $\quad=1.35 \mathrm{~m} / \mathrm{s}$

- Roof surface temperature $=53.2^{\circ} \mathrm{C}$

- Pavement surface temperature:

- Concrete $=46.9^{\circ} \mathrm{C}$

- $\mathrm{DGAC}=52.2^{\circ} \mathrm{C}$

- $\mathrm{PAC} \quad=49.9^{\circ} \mathrm{C}$

- grass block $=43.4^{\circ} \mathrm{C}$

- $\mathrm{PICB}=42^{\circ} \mathrm{C}$
- Wall surface temperature:

- Near pavement $=38.75^{\circ} \mathrm{C}$

- Middle $\quad=37.40^{\circ} \mathrm{C}$

- Near roof $\quad=37.67^{\circ} \mathrm{C}$

The simulation result shows that pavement on air temperature is reduced as the height increased. The pattern of air temperature follows the pattern of surface temperature, with air temperature above dense grade asphalt concrete (DGAC) being the highest, followed by permeable asphalt concrete (PAC), concrete, grass block, and the coolest is permeable interlocking concrete block (PICB).

From table 1 can be seen that compared to concrete pavement, air temperature surrounding 1-3rd floor and 6-8th floor is $1.27^{\circ} \mathrm{C}$ higher for DGAC, and $1.03^{\circ} \mathrm{C}$ higher for PAC. Air temperature surrounding $4-5$ th floor is $1.72^{\circ} \mathrm{C}$ higher for $\mathrm{DGAC}$, and $1.48^{\circ} \mathrm{C}$ higher for PAC. Outdoor air temperature above grass block is $0.06^{\circ} \mathrm{C}$ cooler compared air temperature above concrete. Outdoor air temperature above PICB is $0.63^{\circ} \mathrm{C}$ cooler for 1 st floor, while for $2-8$ th floor is $0.18^{\circ} \mathrm{C}$ cooler compared air temperature above concrete. 
Table 2: Effect pavement surface temperature on air temperature

\begin{tabular}{|c|c|c|c|c|c|c|c|c|c|}
\hline \multirow{2}{*}{$\begin{array}{c}\text { Type of } \\
\text { pavement }\end{array}$} & $\begin{array}{c}\text { Surface temp. } \\
\left({ }^{\circ} \mathrm{C}\right)\end{array}$ & \multicolumn{8}{|c|}{ Air temperature $\left({ }^{\circ} \mathrm{C}\right)$} \\
\cline { 3 - 11 } & & $1^{\text {st }} \mathrm{fl}$ & $2^{\text {nd }} \mathrm{fl}$ & $3^{\text {rd }} \mathrm{fl}$ & $4^{\text {th }} \mathrm{fl}$ & $5^{\text {th }} \mathrm{fl}$ & $6^{\text {th }} \mathrm{fl}$ & $7^{\text {th }} \mathrm{fl}$ & $8^{\text {th }} \mathrm{fl}$ \\
\hline Concrete & 46.9 & 37.07 & 36.16 & 36.16 & 35.71 & 35.71 & 35.71 & 35.71 & 35.71 \\
\hline DGAC & 52.2 & 38.34 & 37.43 & 37.43 & 37.43 & 37.43 & 37.43 & 36.98 & 36.98 \\
\hline PAC & 49.9 & 38.10 & 37.19 & 37.19 & 37.19 & 37.19 & 36.74 & 36.74 & 36.74 \\
\hline Grass block & 43.3 & 37.01 & 36.10 & 36.1 & 35.65 & 35.65 & 35.65 & 35.65 & 35.65 \\
\hline PICB & 42.0 & 36.44 & 35.99 & 35.99 & 35.53 & 35.53 & 35.53 & 35.53 & 35.53 \\
\hline
\end{tabular}

\subsection{The Impact of Permeable Pavement Utilization on Building Energy Consumption}

The effect of permeable pavement utilization on energy consumption is simulated using EnergyPlus package in DesignBuilder software. The pavement material and air temperature difference from the previous section are used as the input data. The air temperature difference between each of four types of pavement and concrete pavement is inputted to the simulation to generate NCU main library energy consumption when utilizing each type of pavement as its base.

Actual energy consumption records of NCU main library was obtained for period of January 2010 - May 2011. Air conditioning electricity consumption increased following the air temperature, the electricity consumption was high during summer with peak consumption in August (66.08\% of total energy consumption), and low during winter with lowest consumption in January (18.32\% of total energy consumption). Hourly average AC energy consumption on July 2010 was used as the base reference for EnergyPlus simulation validation.

Result from the EnergyPlus simulation on a day in June shows air conditioning energy consumption at the peak hour reached $3744.57 \mathrm{~kW}$, this value is close to the real energy consumption record on July $2010,3788.400 \mathrm{~kW}$. Thus, it can be assumed that the result of this simulation can approach the real condition.

With concrete pavement as the base reference, at peak hour, the use of DGAC as building base increase the air conditioning (AC) energy consumption by $477.56 \mathrm{~kW}$ and using PAC increase the energy consumption by $399.89 \mathrm{~kW}$. While using grass block reduces the energy consumption by $27.18 \mathrm{~kW}$. The largest reduction is obtained by utilizing grass PICB. PICB reduce the energy consumption by $93.3 \mathrm{~kW}$. Details of the result can be seen in Table 3.

Using the result to represent peak hour energy consumption on summer, in a month during the peak hour, DGAC pavement increase energy consumption by $14326.8 \mathrm{~kW}$, PAC increase the energy consumption by $11996.7 \mathrm{~kW}$. Grass block and PICB reduced the energy consumption by $815.4 \mathrm{~kW}$ and $2799 \mathrm{~kW}$. 
Table 3: Effect pavement surface temperature on air temperature

\begin{tabular}{|c|c|c|c|c|c|c|}
\hline \multirow[t]{2}{*}{ Floor } & \multirow[t]{2}{*}{ Floor area $(\mathrm{m} 2)$} & \multicolumn{5}{|c|}{ Energy consumption (kW) } \\
\hline & & Concrete & DGAC & PAC & GB & PICB \\
\hline Basement & 1811.4 & 442.63 & 499.57 & 487.41 & 443.56 & 424.34 \\
\hline 1 & 1861.2 & 529.77 & 590.17 & 576.76 & 525.82 & 502.46 \\
\hline 2 & 1729.2 & 510.68 & 569.16 & 555.37 & 506.18 & 502.20 \\
\hline 3 & 1343.9 & 407.89 & 453.80 & 443.13 & 404.55 & 400.82 \\
\hline 4 & 1244.9 & 361.99 & 418.29 & 411.61 & 358.60 & 355.56 \\
\hline 5 & 1261.9 & 367.53 & 424.64 & 417.71 & 364.37 & 361.16 \\
\hline 6 & 1261.9 & 368.14 & 425.39 & 401.32 & 365.04 & 361.83 \\
\hline 7 & 1261.9 & 370.65 & 413.80 & 403.76 & 367.22 & 364.05 \\
\hline 8 & 1223.7 & 385.29 & 427.28 & 417.37 & 382.05 & 378.84 \\
\hline \multirow{2}{*}{\multicolumn{3}{|c|}{\begin{tabular}{c|c} 
Total & 3744.57 \\
DGAC/PAC/GB/PICB - concrete
\end{tabular}}} & 4222.13 & 4144.46 & 3717.39 & 3651.27 \\
\hline & & & +477.56 & +399.89 & -27.18 & $\begin{array}{l}-93.3 \\
\end{array}$ \\
\hline
\end{tabular}

\section{Conclusion}

a. Surface temperature difference between five types of pavement was high at noon (dense grade asphalt concrete $/ \mathrm{DGAC}=52.2^{\circ} \mathrm{C}$, permeable asphalt concrete $/ \mathrm{PAC}=49.9^{\circ} \mathrm{C}$, concrete $=46.9^{\circ} \mathrm{C}$, permeable interlocking concrete block $/ \mathrm{PICB}=42^{\circ} \mathrm{C}$, grass block $=$ $43.3^{\circ} \mathrm{C}$ ), but at night all share almost the same temperature.

b. Air temperature above the pavement follows the pattern of pavement surface temperature. At noon, air temperature above DGAC is the highest, followed by PAC, concrete, and grass block. Air temperature above PICB is the lowest.

c. Simulation on eight-storey building shows that compared to concrete pavement, applying DGAC and PAC as the pavement material increase air temperature above the pavement. Air temperature surrounding 1-3rd floor and 6-8th floor is $1.27^{\circ} \mathrm{C}$ higher for DGAC, and $1.03^{\circ} \mathrm{C}$ higher for PAC. Air temperature surrounding $4-5$ th floor is $1.72^{\circ} \mathrm{C}$ higher for $\mathrm{DGAC}$, and $1.48^{\circ} \mathrm{C}$ higher for PAC. Applying grass block may reduce air temperature above the pavement by $0.06^{\circ} \mathrm{C}$. Applying PICB reduce air temperature surrounding 1 st floor by $0.63^{\circ} \mathrm{C}$, while for $2-8$ th floor is $0.18^{\circ} \mathrm{C}$ cooler compared air temperature above concrete.

d. At peak hour on summer, applying DGAC as pavement material increase air conditioning energy consumption by $477.56 \mathrm{~kW}$ (or $14326.8 \mathrm{~kW}$ in a month), applying PAC increase air conditioning energy consumption by $399.89 \mathrm{~kW}$ (or $11996.7 \mathrm{~kW}$ in a month), applying grass block reduce air conditioning energy consumption by $27.18 \mathrm{~kW}$ (or 815.4 $\mathrm{kW}$ in a month). The largest reduction achieved by applying PICB which reduce air conditioning energy consumption by $93.3 \mathrm{~kW}$ (or $2799 \mathrm{~kW}$ in a month).

\section{Acknowledgement}

This study has been funded by the National Science Council of the Republic of China (Taiwan). The author thanks Prof. Jyh-Dong Lin for helpful comments and advices. The author also thanks Chen-Yu Hsu for his help in data collection.

\section{References}

Akbari, H., M. Pomeratz, \& H. Taha. (2001). Cool Surfaces and Shade Trees to Reduce Energy Use and Improve Air Quality in Urban Area. Solar Energy, 70(3), 295-310. 
Andersen CT, Foster IDL, \& Pratt CJ. (1999). The Role of Urban Surfaces (Permeable Pavements) in Regulating Drainage and Evaporation: Development of a Laboratory Simulation Experiment. Hydrological Processes, 13(4), 597-609.

Bay, Joo-Hwa \& Boon-Lay Ong. 2006. Tropical Sustainable Architecture; Social and Environmental Dimensions. UK: Elsevier.

Chan, Seong Aun. Energy Efficiency: Designing Low Energy Buildings Using Energy 10. Paper presented at CPD Seminar August 7, 2004. Retrieved from <http://www.pam.org.my/Library/ cpd_notes/Energy-Efficiency.pdf>

Gartland, Lisa. 2008. Heat Island: Understanding and Mitigating Heat in Urban Areas. UK: Earthscan.

Kubo, K., H. Kido, \& M. Ito. Study of Pavement Technologies to Mitigate the Heat Island Effect and Their Effectiveness. Japan: PWRI. Retrieved from <http://www.pwri.go.jp/ eng/activity/pdf/reports/kubo.06.08.12.pdf>

Lin, Jyh-Dong, Guang-Yan Cheng, \& Cheng-Li Cheng. (2003). Study on the Design Guideline and Regulation of Rainwater Conservation and Infiltration Techniques at Building Site, Sub-project II: The Performance and Experimental Analysis of Porous Pavements. Taiwan: Architecture \& Building Research Institute, Ministry Of Interior, Research Project Report.

Lin, Tzu-Ping, Yu-Feng Ho, \& Yu-Sung Huang. (2007). Seasonal Effect of Pavement on Outdoor Thermal Environments in Subtropical Taiwan. Building and Environment, 42, 4124-4131.

Rose, L.S., H. Akbari, \& H. Taha. (2003). Characterizing the Fabric of the Urban Environment: $A$ Case Study of Greater Houston, Texas. Paper LBNL-51448. Berkeley, CA: Lawrence Berkeley National Laboratory.

U.S. EPA. (2008). Reducing Urban Heat Island: Compendium of Strategies. Washington, D.C.: Author. 